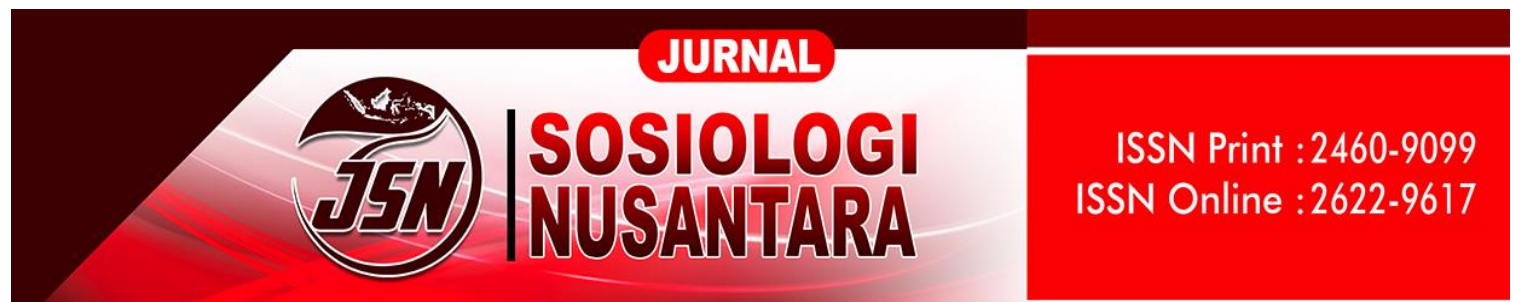

https://ejournal.unib.ac.id/index.php/jsn

DOI ://doi.org/10.33369/jsn.7.2.239-252

\title{
ETNISITAS, BUDAYA POLITIK DAN REALITAS 'ULUN LAMPUNG': DOMINASI DIASPORA JAWA DAN POTENSI DEMOKRASI KOSMOPOLITANISME DI LAMPUNG
}

\author{
ETHNICITY, POLITICAL CULTURE AND THE 'ULUN LAMPUNG': \\ DOMINATION OF THE JAVANESE DIASPORA AND THE POTENTIAL OF \\ DEMOCRATIC COSMOPOLITANISM IN LAMPUNG
}

Dwi Wulan Pujiriyani

lucia_wulan@yahoo.com

Sekolah Tinggi Pertanahan Nasional

\begin{abstract}
Abstrak
Tulisan ini bertujuan untuk membahas demokrasi yang berkembang dalam masyarakat multietnik. Kasus Provinsi Lampung akan menjadi contoh untuk melihat proses-proses akomodatif yang dilakukan bagi kelompok etnik yang tidak dominan. Metode yang digunakan dalam tulisan ini adalah metode studi pustaka dengan pendekatan tematik. Hasil penelitian menunjukan bahwa konteks Lampung belum menunjukkan sebuah praktik demokrasi kosmopolitanisme. Konfigurasi etnis yang ada memang menunjukan sebuah proses akomodatif menuju ke demokrasi kosmopolit. Meskipun demikian, batas-batas yang menjadi wacana di sini masih sangat terbatas antara dua kelompok etnik dominan yaitu etnik Jawa dan etnik Lampung. Pimpinan dari kombinasi etnis yang ada belum menunjukan distribusi kesempatan yang sama bagi kelompok etnik lain yang ada di Lampung. Sebagai dua etnis dominan yang terdikotomi dalam kategori lokal (asli) dan pendatang, emansipasi belum ditunjukan secara eksplisit dimana keberadaan kelompok etnik lain yang ada di Lampung. Variasi kelompok etnik yang ada baru menunjukan bahwa potensi menuju ke demokrasi kosmopolit itu sedang dibangun dengan mengubah persepsi umum bahwa yang dominan akan memenangkan arena kekuasaan.
\end{abstract}

Kata Kunci : Lampung, etnik dominan, pemilihan kepala daerah, demokrasi kosmopolitan 
This paper aims to discuss democracy that develops in multi ethnic societies. The Lampung case will serve as an example to see the accommodative processes carried out for ethnic groups that are not dominant. The method used in this paper is a literature review method with a thematic approach. The results showed that the context of Lampung had not shown a cosmopolitan democratic practice. The existing ethnic configuration does show an accommodative process towards cosmopolitan democracy. However, the boundaries of the discourse here are still very limited between the two dominant ethnic groups, namely the Javanese and the Lampung ethnic groups. The leaders of the existing ethnic combination have not shown equal opportunity distribution for other ethnic groups in Lampung. As the two dominant ethnic groups dichotomized into the local (native) and immigrant categories, emancipation has not been shown explicitly where there are other ethnic groups in Lampung. The variety of existing ethnic groups shows that the potential for leading to cosmopolitan democracy is being built by deconstructing a sense that the dominant will win the arena of power.

Keywords: Lampung, dominant ethnicity, regional head elections, cosmopolitan democracy

\section{PENDAHULUAN}

Etnisitas menjadi semacam tabu politik di Indonesia, negara yang terdiri lebih dari 600 kelompok etnik. Sebagaimana dijelaskan Arifin et al. (2015), tidak mudah mendefinisikan etnisitas. Etnisitas bukanlah budaya, tetapi berkaitan dengan suatu identitas tertentu yang dihasilkan oleh identitas individu dan kelompok, diciptakan dalam konteks ekstrinsik dan intrinsik seperti halnya interaksi sosial. Etnisitas secara umum didefinisikan sebagai rasa keterikatan dengan suatu kelompok yang ditandai dengan asal usul, budaya, bahasa, pengalaman dan nilai-nilai bersama. Etnisitas berbeda dengan ras. Stratifikasi rasial berkaitan dengan status yang diperoleh sejak lahir yang didasarkan pada ciri fisik dan budaya yang dilekatkan oleh orang luar. Seseorang tidak bisa mengubah rasnya. Di sisi lain, meskipun seseorang sudah memiliki status ketika ia lahir, kelompok etnik dapat didefinisikan oleh mereka sendiri sesuai dengan ciri-ciri budayanya.

Sebagaimana dicatat Arifin et al. (2015), anggapan mengenai etnisitas sebagai tabu politik di Indonesia mulai berubah sejak kejatuhan pemerintahan Soeharto setelah 32 tahun berkuasa dan digantikan dengan era reformasi pada tahun 1998. Devolusi kekuasaan pada tahun 1999 telah menghadirkan dampak yang tidak dibayangkan sebelumnya yaitu mendorong fragmentasi teritorial (pemekaran) provinsi dan kabupaten-kabupaten. Fragmentasi ini terlihat jelas di luar Jawa dibandingkan di Jawa. Proses demokratisasi dan desentralisasi juga telah mendorong perkembangan adat dan budaya yang juga menjadi penanda penting di era reformasi dengan kebangkitan kembali identitas etnik. 
Pada awal era reformasi, ketegangan etnik yang bersifat laten dan terakumulasi selama pemerintahan Soeharto, pada akhirnya muncul menjadi konflik dengan kekerasan. Meskipun pemerintah mampu meredamnya, beberapa konflik etnik dan religi tetap terjadi secara sporadis. Salah satu indikasi perubahan dalam demokratisasi di Indonesia adalah penerimaan pemerintah dan masyarakat secara bertahap pada perbedaan etnik, religi dan bahasa. Selama era represif Suharto, etnisitas, agama dan ras seringkali dilekatkan dengan SARA dan merupakan sebuah tabu politis. Isu etnisitas menjadi isu yang sangat sensitif. Hal ini berbeda dengan era reformasi dimana orang-orang bisa lebih bebas mendiskusikan hal-hal yang berkaitan dengan etnisitas. Sekarang, masyarakat Indonesia dapat secara bebas mengekspresikan identitas etniknya.

Dalam konteks kebebasan mengekspresikan identitas etnik inilah, menjadi menarik untuk melihat demokrasi yang berkembang dalam konteks masyarakat dengan kelompok etnik yang relatif homogen yaitu masyarakat dengan kelompok etnik dominan dan beberapa kelompok etnik lain yang berada dalam satu teritorial tertentu. Jamak terjadi bahwa bias kelompok etnik dominan akan mendominasi kelompok etnik lain yang secara kuantitas lebih kecil. Lebih lanjut tulisan ini akan mencoba menelusuri peluang atau potensi demokrasi kosmopolitanisme yang mungkin tumbuh dalam masyarakat yang relatif homogen. Kasus Lampung akan menjadi contoh untuk melihat proses-proses akomodatif yang dilakukan bagi kelompok etnik yang tidak dominan. Pertanyaan yang kemudian dimunculkan adalah bagaimana konfigurasi etnik berkaitan dengan demokrasi kosmopolitanisme yang dijumpai dalam konteks Lampung? Benarkah cerminan demokrasi kosmopolitanisme itu memang mewujud dan siapa saja partisipan yang diakomodasikan atau kategori kelompok-kelompok melintas batas yang dijumpai?

\section{METODE PENELITIAN}

Tulisan ini menggunakan metode pustaka dengan pendekatan tematik. Data dalam tulisan ini diperoleh dari pustaka terkait dengan tema demokrasi dan etnisitas. Sumber kepustakaan yang diambil berasal dari sumber-sumber kepustakaan yang dapat diakses secara online. Kategori kepustakaan yang digunakan dalam tulisan ini termasuk dalam Sumber pustaka yang digunakan terdiri dari sumber sekunder yang berupa artikel review (Ramdhani et al. 2014). Selain itu juga paper atau makalah yang terkait dengan gagasan 
242 I Dwi Wulan Pujiriyani

Etnisitas, Budaya Politik Dan Realitas 'Ulun Lampung': Dominasi Diaspora Jawa

konseptual atau teoritis mengenai etnisitas di Lampung. Sumber pustaka lain yang digunakan adalah opini atau anekdot mengenai praktik demokrasi di Lampung. Analisa data dilakukan secara kualitatif dengan melalui tahapan kategorisasi data, reduksi data dan penyimpulan.

\section{PEMBAHASAN}

\section{Memahami Konsep Demokrasi Kosmopolitanisme}

Kosmopolitanisme merupakan sebuah ideologi yang menjelaskan mengenai seluruh individu sebagai satu kesatuan komunitas yang didasarkan pada moralitas. Sebuah komunitas kosmopolitan mengikat dirinya dengan inklusivitas moral, hubungan ekonomi atau struktur politik yang melingkupi semua perbedaan yang ada. Dalam hal ini pendefinisian kosmopolitan bukan kemudian semata dimaknai bahwa semua penduduk memiliki kesadaran filosofis yang sama, tetapi lebih kepada fakta dimana berbagai latar belakang variasi etnis, budaya, religi, hidup dalam interaksi yang dekat antara satu dengan yang lain. Lentner (2020) mendefinisikan kosmopolitanisme sebagai sebuah politik global, sebuah proyek sosialitas dari politik bersama yang mengikat semua warga dunia dimana sosialitas ini harus memiliki privilege etis atau organisasional dari bentuk-bentuk sosialitas yang lain seperti dapat dicermati dalam kutipan berikut ini:

"Cosmopolitanism can be defined as a global politics that, firstly, projects a sociality of common political engagement among all human beings across the globe, and, secondly, suggests that this sociality should be either ethically or organizationally privileged over other forms of sociality"

Sementara itu, Linklater (1999) menyebut kosmopolitan sebagai gagasan mengenai hak dan kewajiban universal yang mengikat semua orang-orang secara bersama-sama di dalam dunia yang adil dan sejahtera. Konsepsi pertama kewarganegaraan kosmopolitan menekankan akan kebutuhan rasa saling memiliki tidak hanya sebatas nasional saja, melainkan tanggung jawab pribadi terhadap lingkungan dunia. Konsepsi yang kedua berkaitan dengan pengembangan suatu sistem hak asasi manusia yang universal. Adanya kepercayaan bahwa umat manusia secara berangsur-angsur akan semakin dekat dengan kewarganegaraan dunia melalui suatu evolusi hukum kosmopolitan yang melindungi hakhak manusia.

Dalam konteks perlindungan terhadap hak inilah, Beitz (2005) menambahkan bahwa kosmopolitanisme merupakan sebuah teori normatif yang didalamnya menempatkan prinsip-prinsip distribusi keadilan secara khusus. Kosmopolitanisme 
mengadvokasi sebuah komitmen untuk emansipasi manusia dari kesewenang-wenangan kekuasaan dan ketidakadilan yang terjadi dalam berbagai segi. Keadilan yang dikonstruksikan dalam kosmopolitanisme dibangun di atas empat prinsip utama. Pertama, prinsip kesetaraan individu: bahwa individu-individu merupakan unit primer dari moralitas, bukan negara atau bangsa atau kolektivitas yang lain. Kedua, individu memiliki nilai yang setara, oleh karenanya semua individu harus menikmati status yang sama dalam tatanan kelembagaan yang membentuk pilihan-pilihan hidup mereka. Ketiga, empati sebagai dasar atau prasyarat yang dibutuhkan setiap orang untuk bisa saling menghargai antara posisi individu yang satu dengan yang lain. Keempat, bahwa dalam keadilan diprioritaskan kepada mereka yang paling rentan agar bisa mengatasi atau menghilangkan kerugian yang lebih serius.

Selanjutnya, dapat dipahami bahwa demokrasi kosmopolitan merupakan sebuah bahasa etis dan konseptual untuk memikirkan mengenai kondisi politik dan kelembagaan dengan menerapkan nilai-nilai utama dalam demokrasi sosial seperti: aturan hukum, kesetaraan politik, tata kelola pemerintahan yang demokratis, keadilan sosial, solidaritas sosial dan efisiensi ekonomi dalam sebuah sistem transnasional dan sistem global. Archibugi (2004) menambahkan bahwa demokrasi kosmopolitan bukan sebuah norma atau prosedur melainkan sebuah proses. Hal ini diantaranya ditunjukan dengan pengakuan atas hak kaum minoritas ataupun migran. Dalam tulisan ini, demokrasi kosmopolitan dipahami sebagai sebuah konsep demokrasi melintas batas yaitu sebuah sistem demokrasi yang mampu mengintegrasikan perbedaan kelompok yang ada.

\section{Transmigrasi sebagai Akar Diaspora Jawa di Lampung}

Mengacu pada Brubaker (2005), diaspora bukan didefinisikan oleh esensi atau kemurnian, tetapi lebih pada rekognisi heterogenitas dan diversitas melalui konsep identitas dimana dia hidup atau tinggal, bukan sebuah pengecualian, perbedaan atau hibriditas. Dalam konteks diaspora inilah, suku Jawa merupakan suku yang memiliki persebaran sangat luas. Sebagaimana disampaikan Ananta (2015), etnik adalah etnik yang bisa dengan mudah dijumpai di berbagai penjuru Indonesia.

"The Javanese presence can be seen in all Indonesia's provinces. The Javanese were the most ubiquitous ethnic group as they have been seen to be willing to migrate to capture any opportunities everywhere" (Ananta, et all, 2015:140). 
Sebagaimana ditambahkan Pitoyo dan Triwahyudi (2018), Suku Jawa merupakan suku dengan jumlah populasi terbesar di Indonesia. Suku ini merupakan suku yang paling dominan dan tersebar di seluruh wilayah Indonesia. Pulau Jawa telah menjadi panggung sejarah Indonesia selama berabad-abad, dan orang Jawa sebagai kelompok etnis terbesar telah mendominasi lanskap sosial dan politik Indonesia pada masa lampau maupun masa kini. Sekitar 40,06 \% warga negara yang tinggal di Indonesia adalah orang Jawa yang berasal dari tanah kelahiran mereka yaitu Jawa Tengah, Yogyakarta dan Jawa Timur. Sebagaimana disebutkan Arifin et al. (2015), Jawa merupakan kelompok etnik terbesar yang bisa dijumpai di hampir semua provinsi di Indonesia (ubiquity) dengan jumlah 1,5\% populasi di setiap provinsi. Sebagian besar orang Jawa (68,06\% atau 64,55 juta) tinggal di provinsi asal mereka: 33,38\% tinggal di Jawa Tengah, 31,17\% tinggal di Jawa Timur dan 3,51\% tinggal di Yogyakarta. Jawa Tengah merupakan provinsi yang sangat dominan orang Jawa dengan jumlah 97,72\%, disusul kemudian Yogyakarta sebesar 96,53\% dan Jawa Timur 79,72\%. Selain ketiga daerah ini, Jawa Barat, Banten dan Jakarta juga tercatat memiliki populasi orang Jawa yang cukup besar (5,7 juta, 3,4 juta dan 1,6 juta). Sementara itu di luar Jawa, populasi orang Jawa dalam jumlah lebih dari 1 juta orang dapat ditemukan di Lampung, Sumatera Utara, Sumatera Selatan, Riau dan Kalimantan Timur.

Hegemoni atau dominasi budaya Jawa ini bisa terwujud dalam berbagai aspek. Seperti fisik melalui penyebaran permukiman diaspora Jawa di luar tanah air tradisional mereka di Jawa. ${ }^{1}$ Mengacu pada Brubaker (2005), istilah diaspora berakar pada konsep 'homeland' atau kampung halaman (tanah air). Terdapat tiga elemen utama yang dipahami dalam diaspora yaitu: 1) 'dispersion in space' (penyebaran ruang); 2) orientation to a homeland (orientasi pada sebuah tanah air) dan 3) boundary maintenance (mengelola batas). Dalam konteks dispersi, dipahami sebagai pembagian dalam komunitas-komunitas etnik atau sekelompok orang yang tinggal di luar kampung halaman (tanah airnya).Orientasi pada kampung halaman berkaitan dengan nilai, identitas dan loyalitas. ${ }^{2}$ Mengelola batas berkaitan dengan menjaga kekhususan identitas sebagai suatu masyarakat

\footnotetext{
${ }^{1}$ Diaspora sebagaimana disebutkan (Sjaf n.d.) merupakan tradisi seorang migran yang melakukan migrasi, namun tetap berorientasi pada daerah asalnya. Di daerah tujuan migran tersebut, seorang migran tetap mempertahankan identitas tradisi daerah asalnya

2 Orientasi pada kampung halaman ini dapat dibedakan menjadi: pengelolaan memori kolektif atau mitos mengenai kampung halaman; anggapan bahwa tanah leluhur itu benar-benar ada, sebuah rumah impian dan tempat seseorang untuk selalu kembali; berkomitmen untuk menjaga dan memulihkan kampung halaman secara kolektif untuk keamanan dan kemakmurannya; melanjutkan relasi baik dilakukan sendiri atau oleh orang lain untuk membentuk satu identitas atau solidaritas pada kampung halaman
} 
yang berbeda dengan tuan rumah. Batas-batas dapat dikelola dengan sengaja untuk tidak mengasimilasikan diri melalui endogami atau bentuk-bentuk pemisahan diri yang lain atau melakukan semacam eksklusi sosial.

Keberadaan orang Jawa di berbagai provinsi Indonesia merupakan bagian penting yang tidak dapat dilepaskan dari pelaksanaan program transmigrasi. Lampung merupakan provinsi pertama yang menjadi tempat tujuan transmigran seperti dapat dicermati dalam apa yang disampaikan oleh Swasono \& Singarimbun (1986) berikut ini:

"Telah berlalu 80 tahun sejak rombongan transmigran (kolonis) pertama sebanyak 155 kepala keluarga diberangkatkan dari Pulau Jawa ke Lampung pada bulan November 1905. Mereka ditempatkan di desa inti pertama yang dibangun di Gedong Tataan, di tepi jalan Kota Agung, 25 kilometer sebelah barat Tanjungkarang."

Setelah ratusan kepala keluarga dari Bagelen diangkut ke Lampung, gelombang pemindahan penduduk dari Pulau Jawa pun terus berlanjut. Gelombang pertama tahun 1905 hingga 1911. Gelombang kedua tahun 1911 hingga tahun 1939. Gelombang ketiga terjadi ketika Indonesia sudah merdeka. Setelah merdeka, program perpindahan penduduk dari Jawa ke Lampung itu pun dilanjutkan. Namanya bukan kolonisasi, tetapi transmigrasi. Pada periode tahun 1950-1969 perpindahan penduduk ke Lampung mencapai 53.263 keluarga atau sebanyak 221.035 jiwa. Memasuki era Pembangunan Lima Tahun (Pelita), Lampung mendapat lagi tambahan penduduk sebanyak 22.362 kepala keluarga asal Jawa, Madura, dan Bali. Gencarnya perpindahan penduduk itu berdampak pada terjadinya ledakan penduduk. Kalau pada tahun 1905 penduduk Lampung kurang dari 150 ribu dan didominasi suku asli Lampung, kini orang Jawa di Lampung mencapai sekitar 60 persen dari total penduduk Lampung sebanyak 7 juta jiwa. ${ }^{3}$ Orang-orang Jawa yang berpartisipasi dalam program transmigrasi di Lampung inilah yang bisa menjelaskan banyaknya jumlah orang Jawa yang ada di Lampung saat ini. Selain Lampung, daerah tujuan transmigrasi lain yang juga memiliki jumlah etnik Jawa yang cukup banyak adalah di Sumatera Utara (33,40\%), Kalimantan Timur (30,24\%), Riau (29,20\%), Jambi $(29,09 \%)$, Sumatera Selatan (27,41\%) dan Bengkulu (22,64\%) dan Papua Barat (14,76\%). Sebagaimana disebutkan oleh Arifin et al. (2015), Lampung merupakan provinsi yang

Tak hanya barang-barang yang mereka bawa dari Jawa Pulau Jawa. Para transmigran itu juga membawa nama desa dan kebudayaan mereka di tanah yang baru. Maka, sambil membuka hutan menjadi areal pertanian, para transmigran itu juga membangun desa-desa dan melanjutkan tradisi budayanya.Kesenian Jawa seperti wayang kulit, ketoprak, gending-gending Jawa, tayub, dan reog pun hingga kini juga berkembang di daerah-daerah kolonis (transmigrasi) di Lampung. 
relatif homogen. Hal ini ditunjukan dengan keberadaan kelompok etnik dominan yang secara kuantitas melebihi separuh dari jumlah total penduduk di provinsi ini seperti dapat dicermati pada Gambar 1.

Gambar 1. Komposisi Etnik di Lampung

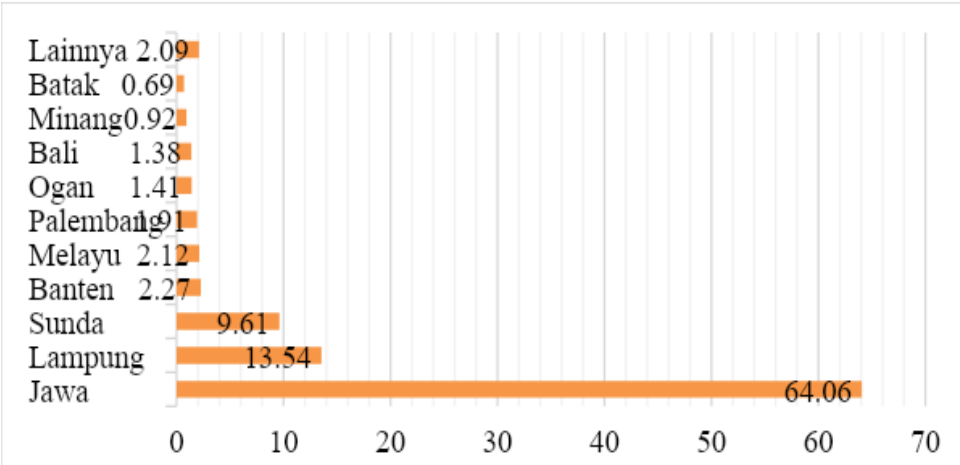

Sumber : Ananta et all, 2015

Jumlah orang Jawa di Lampung mencapai 64,06 \% atau berjumlah 4,856,805. Jumlah ini empat kali lipat lebih besar dari jumlah etnik asli Lampung yang hanya 13,54\% atau berjumlah 1,026,692. Situasi ini tentunya sangat rentan dimuati berbagai isu etnisitas mengingat etnis Jawa di Lampung adalah etnis migran (pendatang) yang akhirnya justru mendominasi.

Etnik Lampung sendiri sering disebut dengan istilah ulun Lampung (orang Lampung. Lampung merupakan kelompok etnik yang cukup kompleks terdiri dari tiga lapis: sub etnik, sub-sub etnis dan sub-sub-sub etnik. Kelompok etnik Lampung ini merupakan penduduk asli yang berasal dari Lampung. Lampung memiliki dua kelompok sub etnis yaitu Saibatin dan Pepadun. Dahulu kelompok etnik di Lampung diklasifikasikan menjadi Lampung Papadun dan Lampung Peminggir.

Tabel 1. Kelompok Etnik dan Sub-etnik Lampung

\begin{tabular}{lccc}
\hline $\begin{array}{c}\text { Kelompok } \\
\text { Etnik }\end{array}$ & Sub-etnik & Sub-sub etnik & Sub-sub-sub etnik \\
\hline & & & \\
\cline { 3 - 4 } & & Semangka & - \\
\cline { 3 - 4 } & Seibatin \\
\cline { 3 - 4 } & $($ Peminggir $)$ & SkalaBrak & Bunga Mayang \\
\cline { 3 - 4 } & & Skala Brak & Abung \\
\cline { 3 - 4 } Lampung & & Telintang-Rajabasa & - \\
\cline { 3 - 4 } & & Krui & - \\
\hline
\end{tabular}




\begin{tabular}{|c|c|c|}
\hline & Belalau & - \\
\hline \multirow{4}{*}{$\begin{array}{l}\text { Pepaduan } \\
\text { (Papadun) }\end{array}$} & Siwo Megau & Sembilan Marga \\
\hline & Buay Lima & - \\
\hline & Megau Pak Tulang Bawang & - \\
\hline & Pubian (Pubiyan) & Pubian Telu Suku \\
\hline
\end{tabular}

Sumber : Arifin et al. 2015

Kelompok etnik di Lampung bukanlah kelompok etnik terbesar di provinsinya sendiri. Orang Jawa merupakan kelompok etnik terbesar yang ada di Lampung dengan jumlah 64,06\%. Hal ini sekali lagi ditegaskan oleh Arifin et al. (2015) merupakan bagian dari sejarah Lampung yang menjadi provinsi pertama yang menjadi tujuan transmigrasi dimana ketika itu penduduk dari daerah-daerah padat di Jawa dan Bali, dipindahkan ke daerah yang kurang penduduknya di luar Jawa. Tercatat bahwa etnik asli Lampung hanya menjadi etnik terbesar kedua dengan jumlah persentase yang kecil yaitu 13,54\%.

\section{Ulun Lampung Versus Orang Jawa: Skenario Jawanisasi di Lampung?}

Seperti dijelaskan dalam penelitian Sinaga (2014), derasnya pendatang yang masuk ke Lampung menyebabkan terpinggirnya posisi ulun Lampung sebagai etnis lokal. Para pendatang di Lampung berkembang menjadi lebih dominan. Kepemilikan sebagian besar tanah di Lampung berpindah tangan dari etnik lokal ke pendatang. Dominasi pendatang sangat terasa bersama pola penamaan daerah yang berkembang sejak masa transmigrasi. Pendatang memberi nama tempat barunya sesuai daerah asal mereka di Jawa seperti: Bagelen, Purworejo, Banyumas, Wonosobo, Purbolinggo, Pringsewu, Surabaya, Yogyakarta, Mataram, Bantul, Sidodadi, Sidomulyo dan lain-lain.

Pengalaman transmigrasi yang telah dimulai pada periode kolonial dengan pengiriman sejumlah besar etnis Jawa ke berbagai pulau di luar Jawa merupakan bagian dari proses yang disebut Arndt and Sundrum (1977) sebagai 'Javanisasi'. Dalam perspektif sosial, budaya dan politik Indonesia, Jawanisasi bisa berarti hanya sebagai penyebaran penduduk suku Jawa dari pedesaan Jawa yang berpenduduk padat ke bagian yang kurang penduduknya di pulau lainnya di Nusantara, sementara itu Niels Mulder menyebut jawanisasi sebagai penerapan sadar atau tidak sadar pola pikir dan perilaku Jawa di berbagai tempat di Indonesia.

Sebagaimana disebutkan Elmhirst (2000), jawanisasi dalam transmigrasi ditandai dengan adanya homogenisasi melalui pemukiman kembali transmigran-transmigran dari 
Jawa di wilayah-wilayah yang jauh (luar Jawa) dengan mengintensifkan kehadiran orangorang Jawa dari pusat ke daerah-daerah pinggiran. Proses-proses dominasi budaya di Indonesia sebagai akar dari negara Jawa merupakan sebuah metafora dan pusat geografis. Dari sinilah kemudian dikenal terminologi 'inner' Indonesia (Jawa dan Bali) dengan 'outer' Indonesia (pulau-pulau yang lain). Ditambahkan dalam Elmhirst (1999), transmigrasi lokal tidak semata merupakan wujud representasi ruang yang disebabkan oleh kekuatan politik dan ekonomi, tetapi juga merupakan sebuah proyek budaya. Transmigrasi merupakan proyek yang penting untuk memproduksi keindonesiaan yang sejalan dengan ruang budaya yang diimajinasikan dengan istilah 'Jawa'. Transmigrasi disebut sebagai sebuah praktik homogenisasi budaya yang mengacu pada 'jawanisasi'yaitu penyebaran nilai-nilai, keyakinan dan cara hidup Jawa ke wilayah-wilayah yang ditinggali oleh kelompok budaya-kelompok budaya non-Jawa.

Terdapat empat representasi 'kejawaan' yang muncul dalam pengelolaan transmigrasi di Lampung. Pertama adalah budaya politik Indonesia yang didominasi oleh hegemoni kultural Jawa. Departemen Transmigrasi dipimpin oleh orang-orang Jawa dimana kemudian kebijakan-kebijakan pun diterjemahkan oleh staf-staf yang juga berasal dari Jawa. Selain identitas budaya dari para pemimpin politik, pengorganisasian komunitas dalam pemukiman transmigrasi juga dibuat dalam model 'desa dimana paham desa yang dibangun dan diidealkan adalah 'desa versi Jawa', dibagi dalam rukun dan bersifat hierarkis. Hal ini berbeda dengan konsep teritorial lokal seperti di Lampung yang berbasis genealogi, non teritori dan non hierarki. Kedua adalah arsitektur bangunan di daerah transmigrasi lokal yang dibangun dengan konsep 'pendapa Jawa', bangunan dengan empat tiang utama tanpa dinding. Ketiga adalah seremoni atau tradisi Jawa seperti gotong royong dan slametan yang dibuat dalam versi Jawa. Yang terakhir adalah agroekologis Jawa yang muncul dalam model pertanian khas Jawa (padi irigasi).

Representasi kejawaan dalam berbagai wujudnya, telah menempatkan migran Jawa secara berbeda dengan masyarakat asli. Transmigran dari Jawa mendapatkan legitimasi khusus dari pemerintah dengan berbagai fasilitasi yang diberikan. Dalam sejarahnya, sejak awal para transmigran dari Jawa ini secara politik lebih dekat dibandingkan dengan tetangga mereka orang Lampung. Selain karena kedekatan spasial dengan pemukiman orang Lampung, desa-desa migran disatukan dalam struktur administrasi pemerintahan nasional, yang menghendaki adanya kepala dan sekretaris dengan fungsi-fungsi yang berbeda dengan desa-desa masa kini. 


\section{Potensi Demokrasi Kosmopolitan di Lampung}

Transmigrasi di Lampung meninggalkan jejak pada konfigurasi etnis dalam kekuasaan. Setting kolonial telah menempatkan masyarakat Lampung ke dalam margamarga dimana kekuasaan bersifat menyebar dan tidak terpusat pada satu kelompok orang atau marga. Sebagaimana jawanisasi yang telah meninggalkan warisan hadirnya orangorang Jawa sebagai etnis dominan di provinsi Lampung, sejarah juga tidak bisa menghapuskan bahwa banyak privilese yang diterima oleh orang-orang Jawa yang ada di Lampung. Sebelum era reformasi, tercatat bahwa kebanyakan setiap daerah di Lampung dikepalai dan dikuasai oleh suku mayoritas yaitu Jawa. Berpuluh-puluh tahun, Lampung dikuasai pemimpin berlatar belakang etnis Jawa.

Kondisi ini mengalami perubahan pasca reformasi dan otonomi daerah. Sebagaimana dijelaskan Prabowo and Suparman (2005), walaupun tergolong minoritas, etnik lokal Lampung pada akhirnya berperan utama dalam jajaran pemerintah daerah. Banyak desa yang mayoritas penduduknya Jawa memilih kepala desa orang Lampung untuk menyelesaikan sengketa tanah. Keberadaan etnik lokal Lampung ini juga bisa ditemukan dalam jajaran pejabat, anggota DPRD dan pengadilan yang didominasi penduduk asli.

Dalam konteks Lampung, isu etnisitas yang mengemuka kemudian adalah komposisi koalisi Lampung-Jawa dan Jawa-Lampung sebagai pemimpin ideal karena dianggap mewakili mayoritas masyarakat Lampung. Hasil penelitian Munaleza dkk. (2010), menunjukan bahwa terjadi perubahan nyata yang berangsur terlihat dari koalisi etnis pada pilkada tahun 2005 sampai dengan yang terakhir pilkada di Lampung Utara tahun 2013. Etnis Lampung yang terpilih menjadi kepala daerah lebih dari $60 \%$ dari total kepala daerah, baik di level kabupaten, kota, maupun provinsi.

Pada tahun 2005 ketika pilkada pertama kali digelar, dari enam pilkada di kabupaten/kota dua wilayah Way Kanan dan Lampung Tengah kepala daerahnya beretnis Lampung, sementara tiga pasangan beretnis Jawa dan satu pasangan beretnis berasal dari wilayah Sumatera Selatan, sedangkan untuk posisi wakil kepala daerah lima beretnis Lampung dan satu bertenis Jawa. Dua tahun kemudian, pada 2007, dari total empat pilkada semua kepala daerah beretnis Lampung, sementara tiga wakil kepala daerah beretnis Jawa dan satu beretnis Lampung. Pada 2008 koalisi etnis Lampung dan Jawa sebagai gubernur dan wakil gubernur. Pada 2010, dari total enam kepala daerah, empat 
kepala daerah beretnis Lampung dan dua beretnis Jawa, semetara untuk posisi wakil kepala daerah tiga beretnis Lampung, dua bertenis Jawa, dan dua beretnis yang berasal dari wilayah Sumatera Selatan. Pada tahun 2011, dari tiga pilkada yang terpilih, dua beretnis Jawa dan satu beretnis Lampung. Pada 2012, dari tiga pilkada yang terpilih, semuanya beretnis Lampung, sementara untuk posisi wakil dua beretnis Jawa dan satu beretnis Jawa. Diakhiri pada 2013 satu pilkada menghasilkan pasangan koalisi etnis Lampung terpilih menjadi kepala dan wakil kepala daerah di Lampung Utara.

Suksesi kepemimpinan sebagai salah satu arena demokrasi yang ditunjukan dengan mengakomodasi partisipasi etnik lokal dengan etnik pendatang dengan jumlah yang justru dominan, merupakan sebuah realitas yang memberikan gambaran mengenai konfigurasi etnik dalam sektor politik di Lampung. Sejauh mana kemudian pemimpin-pemimpin dari etnis tersebut menjadi simbol atau benar-benar sudah merupakan bagian dari proses demokrasi melintas batas dengan mengedepankan kesetaraan pada kelompok-kelompok yang ada, nampaknya masih memerlukan pembuktian yang lebih jauh.

Tabel 2 Kombinasi Etnik Kepala Daerah/Provinsi Lampung Tahun 2005-2015

\begin{tabular}{clcc}
\hline No & \multicolumn{1}{c}{ Kombinasi Etnik } & Jumlah & Persentase \\
\hline 1 & Lampung-Jawa & 7 & 21,21 \\
\hline 2 & Jawa-Lampung & 9 & 27,27 \\
\hline 3 & Lampung-Palembang & 2 & 6,06 \\
\hline 4 & Lampung-Lampung & 15 & 45,45 \\
\hline & Jumlah & 33 & 100,00
\end{tabular}

Sumber: Rahmaini,2017

Dalam hal ini, konteks demokrasi kosmopolitan lebih tepat ditempatkan sebagai potensi dan belum sebagai sebuah realisasi. Konteks 'kosmopolitan' tidak cukup berhenti pada komposisi dua etnis lokal yang dominan secara kuantitas namun seharusnya mampu memberikan konfigurasi yang lebih beragam dengan pelibatan etnik lain yang juga menjadi bagian dari kelompok etnik yang ada di Lampung.

\section{KESIMPULAN}

Demokrasi melintas batas adalah konsep dasar untuk memahami demokrasi kosmopolitanisme. Berkaitan dengan konsep kosmopolitanisme, perlu diingat bahwa kosmopolitanisme mengadvokasi sebuah komitmen untuk emansipasi dengan 4 prinsipnya yang utama yaitu kesetaraan individu; individu sebagai unit primer dari moralitas; empati 
sebagai dasar saling menghargai antar individu; serta prioritas keadilan kepada mereka yang paling rentan. Jika dilihat dari keempat prinsip ini, demokrasi yang berkembang dalam arena kekuasaan belum mencerminkan realitas demokrasi kosmopolit. Pimpinan dari kombinasi etnis yang ada belum menunjukan distribusi kesempatan yang sama bagi kelompok etnik lain yang ada di Lampung. Sebagai dua etnis dominan yang terdikotomi dalam kategori lokal (asli) dan pendatang, emansipasi belum ditunjukan secara eksplisit dimana keberadaan kelompok etnik lain yang ada di Lampung. Variasi kelompok etnik yang ada baru menunjukan bahwa potensi menuju ke demokrasi kosmopolit itu sedang dibangun dengan mendekonstruksi sebuah commonsense bahwa yang dominan akan memenangkan arena kekuasaan.

Selanjutnya, juga bahwa demokrasi kosmopolitanisme adalah bahasa etis dan konseptual yang menerapkan nilai-nilai utama dalam demokrasi sosial seperti: aturan hukum, kesetaraan politik, tata kelola pemerintahan yang demokratis, keadilan sosial, solidaritas sosial dan efisiensi ekonomi. Aspek-aspek ini tentunya harus melekat dalam praktik-praktik pasca suksesi kekuasaan dan bukan hanya berhenti pada perhitungan atau kuantifikasi keterwakilan atau partisipasi yang lebih melihat pada agregat dan bukan pada nilai-nilai yang akan menjadi pemandu dalam ranah yang bersangkutan. Konteks Lampung belum menunjukan sebuah praktik demokrasi kosmopolitanisme. Konfigurasi etnis yang ditunjukkan memang menunjukan sebuah proses akomodatif menuju ke demokrasi melintas batas. Meskipun demikian, batas-batas yang menjadi wacana disini masih sangat terbatas antara dua kelompok etnik dominan dan belum pada aras emansipasi yang diharuskan.

\section{DAFTAR PUSTAKA}

Archibugi, Daniele. 2004. "Cosmopolitan Democracy and Its Critics: A Review." European Journal of International Relations 10(3):437-473+491. doi: 10.1177/1354066104045543.

Arifin, Evi Nurvidya, Aris Ananta, Dwi Retno W, Wahyu Utami, Nur Budi H, and Agus Pramono. 2015. "Quantifying Indonesia's Ethnic Diversity: Statistics at National, Provincial, and District Levels." Asian Population Studies 11(3):233-56. doi: 10.1080/17441730.2015.1090692.

Arndt, H. W., and R. M. Sundrum. 1977. "Transmigration: Land Settlement or Regional Development?" Bulletin of Indonesian Economic Studies 13(3):72-90. doi: 10.1080/00074917712331333204. 
Beitz, Charles R. 2005. "Cosmopolitanism and Global Justice." Journal of Ethics 9(12):11-27. doi: 10.1007/s10892-004-3312-0.

Brubaker, Rogers. 2005. "The 'diaspora' Diaspora." Ethnic and Racial Studies 28(1):119. doi: 10.1080/0141987042000289997.

Elmhirst, Rebecca. 1999. "Space, Identity Politics and Resource Control in Indonesia's Transmigration Programme." Political Geography 18(7):813-35. doi: 10.1016/S0962-6298(99)00029-3.

Elmhirst, Rebecca. 2000. "A Javanese Diaspora? Gender and Identity Politics in Indonesia's Transmigration Resettlement Program." Women's Studies International Forum 23(4):487-500. doi: 10.1016/S0277-5395(00)00108-4.

Lentner, Howard H. 2020. "Globalization and Politics." Power and Politics in Globalization 9-28. doi: 10.4324/9780203335567-6.

Linklater, Andrew. 1999. "The Evolving Spheres of International Justice." International Affairs 75(3):473-82. doi: 10.1111/1468-2346.00088.

Munaleza, Dega O, Susilo Utomo, and Fitriyah Fitriyah. 2010. "Etnisitas Dan Politik Lokal Provinsi Lampung (Studi Kasus Etnisitas Pada Pemilukada Lampung Selatan 2010)." Journal of Politics and Government Studies 3(2):376-85.

Pitoyo, Agus J, and Hari Tri Wahyudi. 2018. "Dinamika Perkembangan Etnis Di Indonesia Dalam Konteks Persatuan Negara." Populasi 25(1):64. doi: 10.22146/jp.32416.

Prabowo, Hendro, and Agus Suparman. 2005. "Masalah Etnisitas Dan Tata Ruang Di Indonesia." Proceeding. Seminar Nasional PESAT 1-11.

Rahmaini, Putri. 2017. "Sikap Etnis Jawa Dan Lampung Terhadap Pluralitas Etnis Calon Pada Pemilihan Kepala Daerah Di Kabupaten Pringsewu Tahun 2017. Studi Pada Masyarakat Etnis Jawa Dan Lampung." Universitas Lampung.

Ramdhani, Abdullah R, Muhammad Ali, Amin, Abdusy S. 2014. "Writing a Literature Research Paper: A Step-by-Step Approach." International Journal of Basics and Applied Science 3(01):47-57.

Sinaga, Risma M. 2014. "Disertasi Revitalisasi Tradisi : Strategi Mengubah Stigma." (1969):109-26.

Sjaf, Sofyan. n.d. "Identitas , Migran Dan Konflik Di Indonesia.” 1-11.

Swasono, Sri E, Singarimbun, Masri. 1986. Transmigrasi Di Indonesia 1905-1985. 1st ed. Jakarta: Ui Press. 
Jurnalsosiologi Nusantara

Vol 7, No 2, Tahun 2021 I 253 